\title{
Comparison of Postoperative Outcome with Diclofenac Rectal Suppositories Versus Intramuscular Diclofenac in Patients Undergoing Laparoscopic Cholecystectomy
}

\author{
Zafar Ali Choudry, ${ }^{1}$ Muhammad Saleem Iqbal, ${ }^{2}$ Munawer Nadeem, ${ }^{3}$ Salman Zafar, ${ }^{4}$ Noor-ul-Huda ${ }^{5}$
}

1Department of Surgery, Vice Chancellor, Faisalabad Medical University, Faisalabad-Pakistan, ${ }^{2 D}$ Department of Surgery, Faisalabad Medical University, Faisalabad-Pakistan, ${ }^{3}$ Department of Surgery, Sialkot Medical College, Sialkot-Pakistan, 4,5Department of Surgery, Jinnah Hospital, Lahore-Pakistan

\begin{abstract}
Objective: The aim of this study was to compare postoperative outcome with diclofenac rectal suppositories versus intramuscular diclofenac in patients undergoing laparoscopic cholecystectomy. Study Design: Randomized Controlled Trial. Settings: General surgery Department, Khawaja Muhammad Safdar Medical College Sialkot \& Allied Hospital Faisalabad Pakistan. Duration: 2 year from May 2017 to April 2019. Methodology: After informed consent, 200 patients scheduled for laparoscopic cholecystectomy were randomized into two groups. Group-A got diclofenac sodium rectal suppository at time of induction of anesthesia and Group-B were given IM Diclofenac for postoperative pain relief. Assessment of pain was done using Visual Analogue Scale (VAS) by an observer which will be graded ruler ranging from 0-10 showing the minimal and maximum pain score respectively. The score was assessed post operatively at recovery time 6,12 and 24 hours. Activity score was checked at $8,12 \& 24$ hours postoperatively. Data was collected for pain \& mobility through specially designed Performa. Results: Demographic characteristics, intraoperative and postoperative hemodynamics of the patients were similar between groups. Postoperative VAS were lower at all-time points in Group -A. Mean VAS was 6.41(SD 0.89), 4.03 (SD 0.92), 2.16 (SD 0.84) in group A as compared to 7.78 (SD 0.83), 5.86 (SD 0.92), 4.4 (SD 1.33) in group B after 6hr, $12 \mathrm{hr}$ \& $24 \mathrm{hr}$. respectively. Mean activity score was 3.28 (SD 0.61), 1.8(SD 0.79), 1.1(SD 0.36) in group A and 4.35 (SD 0.63), 3.31 (SD 0.83), 2.85 (SD) in group $B$ after $8 \mathrm{hr}$., $12 \mathrm{hr}$. and $24 \mathrm{hr}$. respectively. Conclusion: In patients undergoing laparoscopic cholecystectomy, application of diclofenac sodium rectal suppository at time of induction of anesthesia is more effective than IM diclofenac sodium and can be preferred in postoperative pain treatment.
\end{abstract}

Keywords: Diclofenac sodium, Laparoscopic cholecystectomy, Suppository, Postoperative pain, Activity.

Corresponding Author

Submitted for Publication: 14-05-2020

Dr. Muhammad Saleem Iqbal, Assistant Professor, Department of Surgery, Faisalabad Medical University, Faisalabad-Pakistan

Email: drsaleemiqbalmadni@gmail.com

Citation: Choudry ZA, Iqbal MS, Nadeem M, Zafar S, Huda N. Comparison of Postoperative Outcome with Diclofenac Rectal Suppositories Versus Intramuscular Diclofenac in Patients Undergoing Laparoscopic Cholecystectomy. APMC 2020;14(2):179-82.

DOI: $10.29054 / A P M C / 2020.896$

\section{INTRODUCTION}

Laparoscopic cholecystectomy is commonly performed procedure for symptomatic gallstone disease. ${ }^{1}$ Although laparoscopic cholecystectomy causes less pain and discomfort as does open cholecystectomy but still most of patients complain of postoperative pain at port site usually at epigastrium and umbilical port. The pain intensity is more severe in first few hours after surgery. ${ }^{2}$ If pain is not managed properly it may have detrimental effects on cardiovascular system, central nervous system and respiratory system. ${ }^{3}$ The goal of postoperative pain management is to reduce or eliminate the postoperative pain along with minimum side effects. Reduction in postoperative pain ultimately has many positive outcomes like early mobility, early oral intake, early discharge from hospital and ultimately ultimate early return to daily activities. ${ }^{4}$

Most common medication used for control of moderate pain postoperatively is NSAIDS. Opioids were drug of choice initially for postoperative pain but it has higher incidence of side effects like nausea, vomiting, respiratory depression and ileus. NSAIDS do not cause respiratory depression and ileus. ${ }^{5}$

NSAIDS are used by many routes as intramuscular, intravenous, oral, cutaneous patch and rectal routes (suppositories). Suppository has many additional advantages than other routes. It decreases nausea, vomiting and gastritis caused most commonly by oral intake. Suppositories can be used in patients who are nil by mouth postoperatively. Rectal suppository has advantage over intramuscular route that first pass metabolism is avoided and also absorption of diclofenac is more with rectal rout than with intramuscular route. Thus, rectal suppository represents simple and effective analgesia postoperatively in patients undergoing laparoscopic cholecystectomy. ${ }^{6}$

When NSAIDS are given intramuscularly their administration is painful and they usually require rescue analgesia in the form of opioids to control postoperative pain in patient who has undergone laparoscopic cholecystectomy. ${ }^{7}$ Different studies conducted on patients of laparoscopic cholecystectomy have favored that Diclofenac suppository in $100 \mathrm{mg}$ dose significantly decrease VAS score and reduce requirement of rescue analgesia.

Rationale of current study is to check the effect of diclofenac rectal suppositories on postoperative outcome such as postoperative pain and mobility. Commonly intramuscular injection of NSAIDS is given to relieve postoperative pain in our 
set up. This study will provide roadmap to use rectal suppositories as effective alternative to intramuscular diclofenac sodium injection in postoperative effective relief of pain ultimately leading to early return to home \& activity.

Objectives: The objective of the study is comparison of postoperative outcome with diclofenac rectal suppositories and intramuscular diclofenac in patients of laparoscopic cholecystectomy.

\section{Operational Definitions}

1. Visual analogue scale:

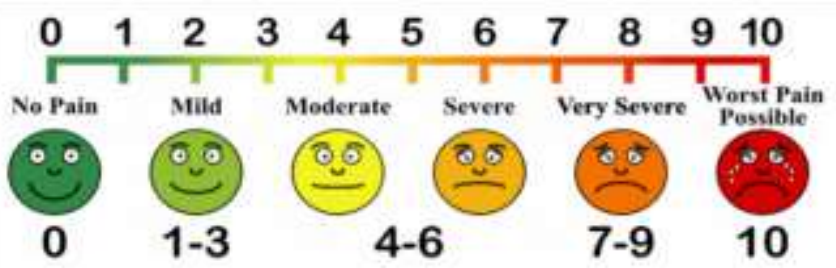

2. Postoperative mobility: It will be assessed at $8,12 \& 24$ hour postoperatively with the help of following scale.

\begin{tabular}{|l|l|l|}
\hline Score & $\begin{array}{l}\text { Maintain standing } \\
\text { position without help for } 3 \\
\text { min }\end{array}$ \\
\hline 3 & $\begin{array}{l}\text { As transferring from } \\
\text { sitting to bed, transferring } \\
\text { oneself from \& to sitting } \\
\text { level }\end{array}$ \\
\hline 4 & $\begin{array}{l}\text { Cannot transfer while } \\
\text { sitting but maintain sitting } \\
\text { position without } \\
\text { assistance }\end{array}$ \\
\hline 5 & $\begin{array}{l}\text { Does not maintain sitting } \\
\text { position but change lying } \\
\text { position }\end{array}$ \\
\hline poesition
\end{tabular}

\section{METHODOLOGY}

Study Design: Randomized Controlled Trial.

Settings: General surgery Department, Khawaja Muhammad Safdar Medical College Sialkot \& Allied Hospital Faisalabad Pakistan.
Duration: 2 years from May 2017 to April 2019.

Sample Technique: Non-probability purposive sampling.

Sample Size: Total 200 patients were included in this study (100 in each group)

Inclusion Criteria: Patient with symptomatic gallstone disease between age of 18 and 60 years.

Exclusion Criteria:

1. All known patients with history of upper abdominal surgery.

2. Patient with emphysematous cholecystitis.

3. Patient unfit for general anesthesia.

4. Patients who have comorbid conditions that may interfere with blood loss and pain assessment e.g. Blood dyscrasias, coagulation abnormalities, impaired cognition and limited mobility.

Data Collection Procedure: After the approval of the research proposal from the "Ethical Review Committee" as per inclusion and exclusion criteria all consecutive patients were taken who are admitted in Surgery Department of Khawaja Muhammad Safdar Medical College Sialkot \& Faisalabad Medical University IAllied Hospital or present to Outdoor Patient Department of the Hospital. Informed consent was taken from all the patients for all investigations and the use of data for research purpose. Total 200 patients were selected for the study, who were randomly divided into two equal groups by using computer generated random number tables.

Group-A patients were given Diclofenac suppositories at the time of induction of anesthesia and Group-B were given IM Diclofenac for postoperative pain relief. Assessment of pain was done using Visual Analogue Scale (VAS) by an observer which will be graded ruler ranging from 0-10 showing the minimal and maximum pain score respectively. The score was assessed post operatively at recovery time 6,12 and 24 hours. Activity score was checked at $8,12 \& 24$ hours postoperatively. Data was collected for pain \& mobility through specially designed Performa.

Data Analysis Procedure: All the data was analyzed using the SPSS v-19. Mean, range, median and standard deviation were calculated for all quantitative variables like age, Postoperative Activity Score and Post-operative Pain. Frequency and percentage were calculated by all qualitative variables like gender. Independent sample t-test was used to compare postoperative mobility and post-operative pain in both groups. Effect modifiers like age and gender were controlled by stratification. Post-stratification Independent sample t-test was applied. Pvalue $<0.05$ was taken as significant.

\section{RESULTS}

Table 1: Baseline Characteristics of Patients (Gender)

\begin{tabular}{|c|c|c|c|c|}
\hline & Frequency & Percent & $\begin{array}{c}\text { Valid } \\
\text { Percent }\end{array}$ & $\begin{array}{c}\text { Cumulative } \\
\text { Percent }\end{array}$ \\
\hline Male & 102 & 51.0 & 51.0 & 51.0 \\
\hline Female & 98 & 49.0 & 49.0 & 100.0 \\
\hline
\end{tabular}




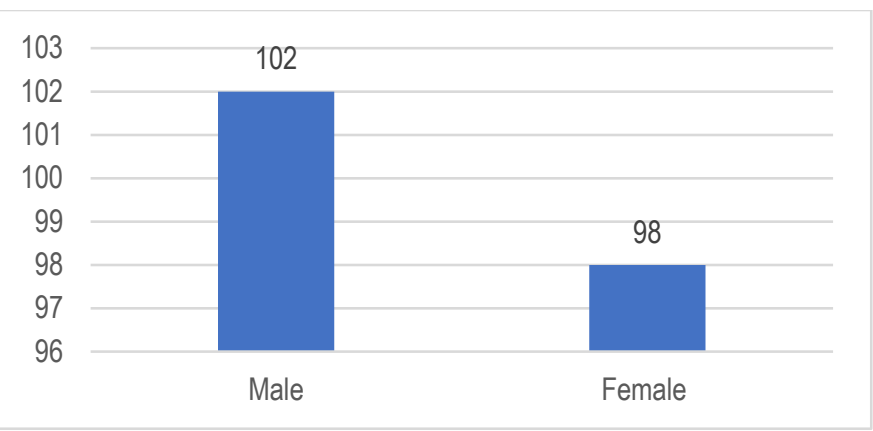

Figure 1: Sex Distribution

Table 2: Parameters of Group A

\begin{tabular}{|c|c|c|c|c|c|c|c|}
\hline Parameter & Age & $\begin{array}{c}\text { VAS } \\
\mathbf{6 h r} .\end{array}$ & $\begin{array}{c}\text { VAS } \\
\mathbf{1 2 h r}\end{array}$ & $\begin{array}{c}\text { VAS } \\
\mathbf{2 4 h r} .\end{array}$ & $\begin{array}{c}\text { AS } \\
\mathbf{8 h r} .\end{array}$ & $\begin{array}{c}\text { As } \\
\mathbf{1 2 h r} .\end{array}$ & $\begin{array}{c}\text { AS } \\
\mathbf{2 4 h r}\end{array}$ \\
\hline Number & 100 & 100 & 100 & 100 & 100 & 100 & 100 \\
\hline Minimum & $\begin{array}{c}26- \\
35\end{array}$ & 4 & 2 & 1 & 2 & 1 & 1 \\
\hline Maximum & $>55$ & 9 & 6 & 6 & 5 & 4 & 3 \\
\hline Mean & - & 6.41 & 4.03 & 2.16 & 3.28 & 1.8 & 1.1 \\
\hline $\begin{array}{c}\text { Standard } \\
\text { deviation }\end{array}$ & - & 0.889 & 0.915 & 0.838 & 0.604 & 0.79 & 0.362 \\
\hline Range & - & 5 & 4 & 5 & 3 & 3 & 2 \\
\hline Median & - & 6 & 4 & 2 & 3 & 2 & 1 \\
\hline
\end{tabular}

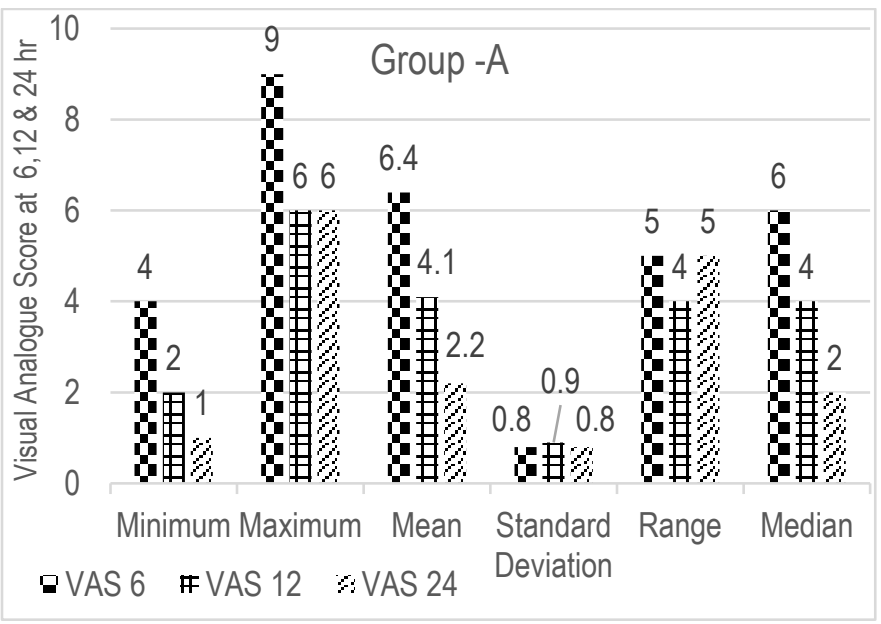

Figure 2: Visual analog scale (VAS) score of group A

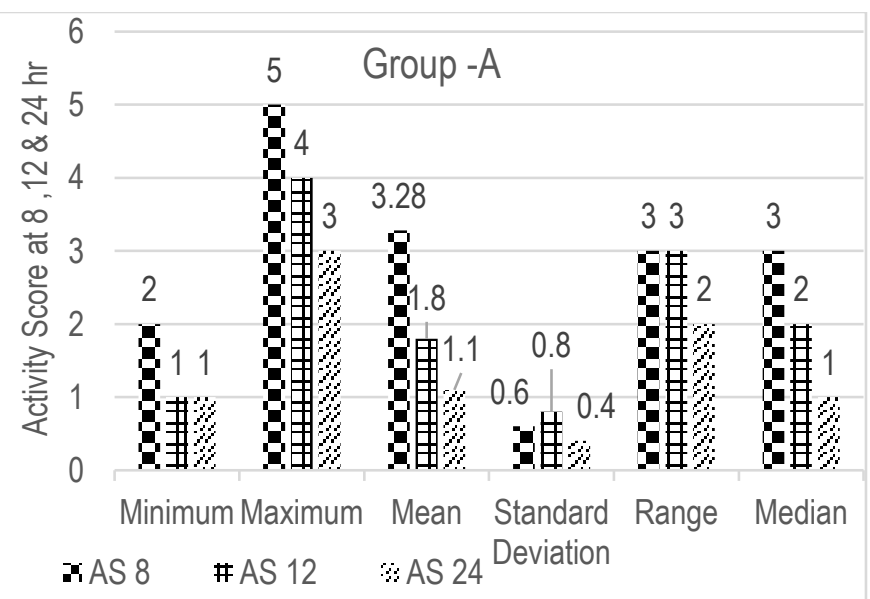

Figure 3: Activity Score (AS) of group A
Table 2: Parameters of Group B

\begin{tabular}{|c|c|c|c|c|c|c|c|c|}
\hline$\#$ & $\begin{array}{c}\text { Paramet } \\
\text { er }\end{array}$ & $\begin{array}{c}\mathrm{Ag} \\
\mathrm{e}\end{array}$ & $\begin{array}{c}\text { VAS } \\
6 \\
\text { hr. }\end{array}$ & $\begin{array}{c}\text { VAS } \\
12 \\
\text { hr. }\end{array}$ & $\begin{array}{c}\text { VAS } \\
24 \\
\text { hr. }\end{array}$ & $\begin{array}{c}\text { AS } \\
8 \\
\mathrm{hr} .\end{array}$ & $\begin{array}{l}\text { As } \\
12 \\
\mathrm{hr} .\end{array}$ & $\begin{array}{l}\text { AS } \\
24 \\
\text { hr. }\end{array}$ \\
\hline 1 & Number & $\begin{array}{c}10 \\
0\end{array}$ & 100 & 100 & 100 & 100 & $\begin{array}{c}10 \\
0\end{array}$ & 100 \\
\hline 2 & Minimum & $\begin{array}{l}26- \\
35\end{array}$ & 6 & 4 & 2 & 3 & 1 & 1 \\
\hline 3 & $\begin{array}{c}\text { Maximu } \\
\mathrm{m}\end{array}$ & $\begin{array}{c}>5 \\
5 \\
\end{array}$ & 9 & 7 & 6 & 5 & 5 & 4 \\
\hline 4 & Mean & - & 7.78 & 5.86 & 4.4 & 4.35 & $\begin{array}{c}3.3 \\
1\end{array}$ & 2.85 \\
\hline 5 & $\begin{array}{l}\text { Standard } \\
\text { deviation }\end{array}$ & - & $\begin{array}{c}0.82 \\
4 \\
\end{array}$ & $\begin{array}{c}0.92 \\
1\end{array}$ & $\begin{array}{c}1.33 \\
3 \\
\end{array}$ & $\begin{array}{c}0.62 \\
6\end{array}$ & $\begin{array}{c}0.8 \\
3 \\
\end{array}$ & $\begin{array}{c}0.79 \\
6\end{array}$ \\
\hline 6 & Range & - & 3 & 3 & 4 & 2 & 4 & 3 \\
\hline 7 & Median & - & 8 & 6 & 4 & 4 & 3 & 3 \\
\hline
\end{tabular}

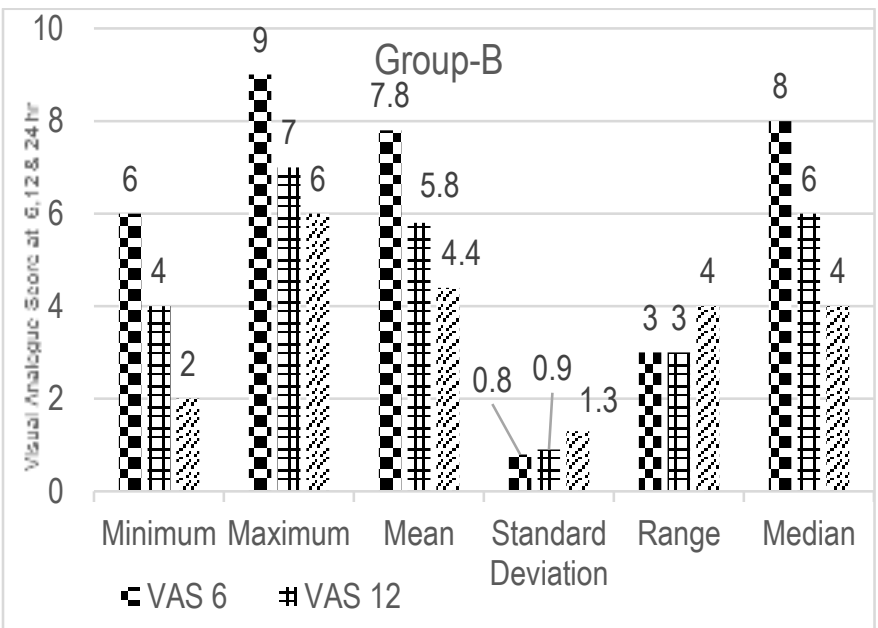

Figure 4: Visual analog scale (VAS) score of group B

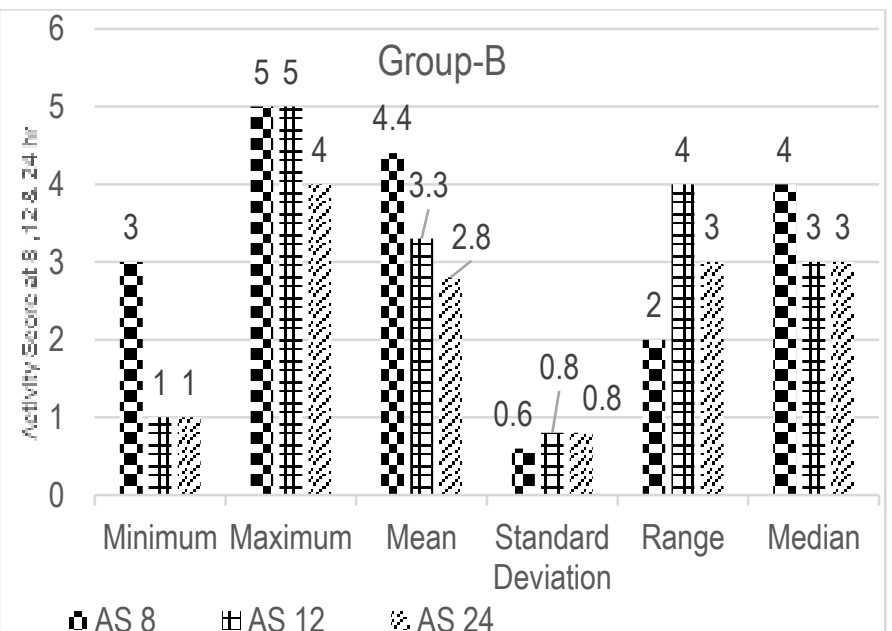

Figure 5: Activity score (AS) of group B

\section{DISCUSSION}

In this study, analgesic efficacies of suppositories and intramuscular forms of Diclofenac sodium following LC were compared. A significant decrease in post-operative VAS values was discovered in Group-A when compared with the Group-B. Post-operative pain peaks in the first hours and is controlled in 
the following hours and gradually decreases in the $2 n d-3 r d$ postoperative days.

When diclofenac suppository is given at time of induction of anesthesia, it blocks noxious stimuli while acting as pre-emptive anesthesia and ultimately improves postoperative outcome. Use of diclofenac suppository is associated with sustained relief of pain for 2-3 hours after surgery. Several studies approve the use of rectal suppository in postoperative analgesia for various procedure. These studies reported significant reduction in postoperative and use of postoperative opioids.

Trans-rectal administration allows complete absorption and sustained release of medication forming rectal suppository as a potent analgesia. Transmission of pain signals evoked by tissue damage lead to sensitization of peripheral and central pain pathway. Mean pain score of in patients receiving rectal suppository is significantly lower than those receiving intramuscular diclofenac. The result is similar to Arab M. et Al (2013) who conducted diclofenac rectal suppository as simple \& safe analgesic in Laparoscopic cholecystectomy ${ }^{9}$.

Patient with rectal suppositories used to move early and have good activity score as compared to group-B patient. This is best explained by effective pain control, better the pain control earlier the patient starts activity. The results of this study are very encouraging. It may be further studied.

\section{CONCLUSION}

In patients undergoing laparoscopic cholecystectomy, application of diclofenic sodium rectal suppository at time of induction of anesthesia is more effective than IM diclofenac sodium and can be preferred in postoperative pain treatment.

\section{LIMITATIONS}

Rectal suppositories are not used in patients having

- Hypersensitivity to the active substance or any of the excipients.

- History of gastrointestinal bleeding or perforation, relating to previous NSAID therapy

- In patients in whom attacks of asthma, angioedema, urticaria or acute rhinitis are precipitated by ibuprofen, acetylsalicylic acid or other NSAID

- Proctitis

\section{SUGGESTIONS / RECOMMENDATIONS}

We recommend use of rectal suppositories in every patient of laparoscopic cholecystectomy to have better outcome.

\section{CONFLICT OF INTEREST / DISCLOSURE}

The authors declare that there is no conflict of interest to be declared.

\section{ACKNOWLEDGEMENTS}

Our sincere appreciation and thanks go to the faculty of surgical unit-1 for their invaluable support and contribution.

\section{REFERENCES}

1. Sahu B, Mishra CS. Effect of pre-operative rectal diclofenac suppository on post-operative analgesic requirement in cleft lip palate repair, SJAMS 2016;4(3):790-2.

2. Ebrahim AJ, Mozaffar R, Nadia BH, Ali J. Early postoperative relief of pain and shivering using diclofenac suppository versus intravenous pethidine in spinal anesthesia. J Anaesthesiol Clin Pharmacol. 2014;30(2):243-7.

3. Sinha S P, Sinha S, Sharma SC, Jain S, Hai A. Efficacy of Tramadol V/s Diclofenac in Management of Post Laparoscopic Cholecystectomy Pain. Int J Scie Study. 2013;1(3):89-94.

4. Paul D, Jacob M, Kulkarni SN. Comparative evaluation of efficacy of intravenous paracetamol and intravenous diclofenac as postoperative analgesia in laparoscopic cholecystectomy. Int J Bio Res. 2015;6(7):482-7.

5. Taneja A, Vidhushi, Kaur T, Sood IV. Comparative Study on The Effect of Paracetamol, Diclofenac and their Combination in PostOperative Pain Relief of Cesarean Section. JK Science. 2015;17(1):30-2.

6. Pal A, Biswas J. Diclofenac is more effective for postoperative analgesia in patients undergoing lower abdominal gynecological surgeries: A comparative study. Anesth Essays Res. 2014;8(2):192-6.

7. Joshi V S, Vyavahare R D, Khade G, Shiledar V, Jamadar NP. Comparative study of analgesic efficacy of rectal suppository of tramadol versus diclofenac in suppressing postoperative pain after Cesarean section. Int $\mathrm{J}$ of Healthcare and Biomedical Research, 2013;1(2):32-7.

8. Abdolraza ghnejad $A$, Banaie $M$, Tavakoli $N$, Safdari $M$, Rajabpour-Sanati A. Pain Management in the emergency department: a review article on options and methods. Adv J Emerg Med. 2018;2(4):e45.

9. Arab M, Motahhar HS, Pazouki A, Tamannaie Z, Arabpour B, Fahimi H. Efficacy of Diclofenac Rectal Suppository in Patients with Laparoscopic Cholecystectomy: A Prospective Randomized Double Blinded Clinical Trial. J Minim Invasive Surg Sci. 2013;2(1):43-5.

10. Mahdavi A, Telkabadi Z, Aleyasin A, Hosseini MA, Safdarian L and Momenzadeh A. Comparison of Morphine Suppository and Diclofenac Suppository for Pain Management After Elective Caesarean Section. Acta Medica Iranica. 2016;54(11):706-12.

11. Ross F. Goldberg, MD. The Opioid Crisis- The Surgeon's Role. Advances in surgery. 2019;53(2):305-25.

12. Senturk AB, Yaytokgil M, Ekici M, Sari S, Demir E, Cakiroglu B. Comparing use of lidocaine periprostatic nerve block and diclofenac suppository alone for patients undergoing transrectal ultrasound guided prostate biopsy. Cent European J Urol. 2018;71(1):38-42.

$\begin{array}{ll}\text { AUTHORSHIP CONTRIBUTION } \\ \text { Zafar Ali Choudry } & \text { Principal Investigator, Manuscript } \\ & \text { Writing } \\ \text { Muhammad Saleem Iqbal } & \begin{array}{l}\text { Literature Review, Data Analysis, } \\ \text { Tabulation }\end{array} \\ \text { Munawer Nadeem } & \text { Data Collection } \\ \text { Salman Zafar } & \text { Data Collection, References Writing } \\ \text { Noor-ul-Huda } & \text { Tabulation of Results }\end{array}$

